\title{
EJECUCIÓN Y CUMPLIMIENTO DE LA PENA DE PRESTACIÓN DE SERVICIOS A LA COMUNIDAD
}

\section{EXECUTION AND ENFORCEMENT OF THE PENALTY TO PROVIDE SERVICES TO THE COMMUNITY}

Yasmina RIEGA-VIRÚ ${ }^{1}$

RESUMEN: La investigación tuvo por objetivo determinar la correlación entre el cumplimiento de la pena y la aplicación de las normas. Se revisaron 150 expedientes con sentencia en Lima metropolitana. Entre los resultados se obtuvo que el INPE en un $31 \%$ toma en cuenta las habilidades de los sentenciados para asignar el trabajo comunitario; en $69 \%$ asigna trabajos comunitarios ajenos a sus habilidades; el $70 \%$ es supervisado de manera discontinua y el $30 \%$ en forma mensual, lo que implica la omisión del informe al juez sobre el trabajo del sentenciado en forma mensual. El 77\% de entidades receptoras no devuelve las planillas de control laboral de los sentenciados; el 33\% sí lo hace; al 54\% les asigna tareas no específicas, y al $46 \%$ en tareas específicas. Con el resultado de la prueba estadístico Chi cuadrada de Pearson $\left(\mathrm{X}^{2}\right)$, para las variables cumplimiento o no cumplimiento de la disposición referida en el artículo 263 del D.S. Núm. 015-2003-JUS- Reglamento del Código de Ejecución penal se obtuvo un valor $X^{2}$ de 44.88 , que permiten establecer que existe correlación. Se concluyó que el incumplimiento del proceso normado está asociado al incumplimiento de la pena de prestación de servicios a la comunidad.

Palabras claves: pena de prestación de servicios a la comunidad, ejecución de pena, entidades receptoras.

ABSTRACT: The objective of this research was to determine the correlation between compliance with the punishment and implementation of standards. 150 records were reviewed with judgment in Lima. Among the results obtained that the INPE 31\% takes into account the skills of those sentenced to assign community work, $69 \%$ assigned outside their community work skills; $70 \%$ is monitored discontinuously and $30 \%$ on a monthly basis; omitting to inform the judge about the work of sentenced monthly. $77 \%$ of entities receiving does not return the forms of job control those sentenced, $33 \%$ if you do; $54 \%$ not assigned specific tasks, $46 \%$ located in specific tasks; $2 \%$ sentenced presents a very unfavorable attitude toward the sentence imposed, $35 \%$ have an unfavorable attitude, $35 \%$ have a favorable attitude and $28 \%$ very favorable attitude. Finally, the test result of the Pearson chi-square statistic $\left(X^{2}\right)$ for the variables compliance or non-compliance of the provision referred to in Article 263 of Supreme

\footnotetext{
${ }^{1}$ Abogada; magíster en derecho penal y doctora en derecho; coordinadora y docente de la Facultad de Derecho de la Universidad Privada del Norte, Lima, Perú.
} 
Esta revista forma parte del acervo de la Biblioteca Jurídica Virtual del Instituto de Investigaciones Jurídicas de la UNAM

Decree Núm. 015-2003-JUS- Rules of Criminal Execution Code - Enforcement of penalties to provide services to the community and limitation of days; and compliance or noncompliance with the judgment by providing sentenced to community service; a value $X^{2}$ of 44.88 , to establish that there is a correlation. It was concluded that the compliance of regulated process is associated with the failure of the penalty provision of services to the community.

Keywords: Penalty Provision of Community Services, Execution of Penalty, Receiving Entities.

SUMARIO: I. Introducción. II. Metodología. III. Resultados. IV. Conclusiones. V. Bibliografía.

\section{INTRODUCCIÓN}

\section{Acerca de la pena de prestación de servicios a la comunidad}

Con el Código Penal de $1991^{2}$ se introdujeron en el Perú las penas limitativas de derechos en sus modalidades de prestación de servicios a la comunidad, la limitativa de días libres e inhabilitación, para ser aplicadas como autónomas o como sustitutivas de la pena privativa de libertad, cuando la pena remplazada en criterio del juzgador no sea superior a tres años (artículo 32).

La pena de prestación de servicios a la comunidad obliga al condenado a trabajos gratuitos en entidades asistenciales, hospitalarias, escuelas, orfanatos, otras instituciones similares u obras, siempre que sean públicos; también puede ejecutarse en instituciones privadas con fines asistenciales o sociales. Los servicios son asignados, en lo posible, conforme a las aptitudes del condenado, debiendo cumplirse en jornadas de diez horas semanales, entre los días sábados, domingos o feriados, de modo que no perjudiquen la jornada normal de su trabajo habitual (artículo 34). ${ }^{3}$

La sanción limitativa se extiende de diez a 156 jornadas de servicio; su incumplimiento tendrá como efecto convertirlas en sanción privativa de libertad. En octubre de 2008 se modifica y se aplica como autónoma cuando está específicamente señalada para cada delito y como sustitutiva o alternativa de la pena privativa de libertad, cuando la sanción sustituida a criterio del juez no sea superior a cuatro años. $^{4}$

\footnotetext{
${ }^{2}$ Código Penal, Decreto Legislativo Núm. 635, Diario Oficial El Peruano, Lima, 8 de abril de 1991.

${ }^{3}$ Articulo modificado por el Decreto Legislativo Núm. 1191, del 21 de agosto de 2015.

${ }^{4}$ Artículo modificado por el artículo único de la Ley Núm. 27186 del 20 de octubre de 1999.
} 
La inclusión de la pena de prestación de servicios a la comunidad en el Código Penal de 1991 tiene su antecedente en el Código Penal de Brasil de 1984, que, a decir de Prado, ${ }^{5}$ en su numeral 32 incorpora dentro de las penas restrictivas de direitos, junto a la inhabilitación, las penas de prestação de servicios á comunidade y de limitação de fin de semana.

En España, señala Santiago Mir, ${ }^{6}$ la pena de trabajos en beneficio de la comunidad se introdujo en 1995, y a partir del ejemplo del community service británico, como un sustitutivo que el juez puede ofrecer al sujeto de penas privativas de libertad; en 2003 se aumentó su uso con la Ley Orgánica 15/2003, y con la Ley Original 5/2010 su contenido ha quedado regulado en el artículo 49 como sigue:

Los trabajos en beneficio de la comunidad, que no podrán imponerse sin el consentimiento del penado, le obligan a prestar su cooperación no retribuida en determinadas actividades de utilidad pública, que podrán consistir, en relación con delitos de similar naturaleza al cometido por el penado, en labores de reparación de los daños causados o de apoyo o asistencia a las víctimas, así como en la participación del penado en talleres o programas formativos o de reeducación, laborales, culturales, de educación vial, sexual y otros similares.

Su duración diaria no podrá exceder de ocho horas. Las penas limitativas de derechos, como dice Ariel Dotti, citado por Prado, son necesarias y suficientes para prevenir y suprimir el crimen, y no trazan la marca de degradación social, como ocurre con la prisión. ${ }^{7}$ Todo lo contrario, identificándose con el sentido democrático de la pena criminal moderna, las restricciones del derecho contribuyen decisivamente para que no se margine al condenado y para que la sanción penal sea también utilitaria.

Hurtado Pozo y Prado Saldarriaga, ${ }^{8}$ citando a Prado, señalan que la pena de prestación de servicios a la comunidad no ha alcanzado aún un rol relevante en la praxis judicial, en la medida en que se la emplea, sobre todo para reprimir faltas. Agregan que su aceptación social también es todavía limitada, debido a factores

\footnotetext{
${ }^{5}$ Prado Saldarriaga, Víctor, Determinación judicial de la pena y acuerdos plenarios, Lima, IDEMSA, 2010, p. 79.

${ }^{6}$ Mir Puig, Santiago, Derecho penal. Parte general, 9a. ed., Buenos Aires, Euros Editores, 2011, pp. 722 y 723.

${ }^{7}$ Prado Saldarriaga, Víctor, Determinación judicial..., cit., p. 79.

${ }^{8}$ Hurtado Pozo, José y Prado Saldarriaga, Víctor, Manual de derecho penal. Parte general, 4a. ed., Lima, IDEMSA, 2011, t. II, pp. 282 y 283.
} 
coyunturales como la crisis del mercado laboral, la desconfianza social en el condenado y la alta tasa de empleo informal, que limitan, de modo considerable, su desarrollo y utilidad. Además, les parece interesante el enfoque y las expectativas de la administración penitenciaria sobre la situación actual de la prestación de servicios a la comunidad. Se afirma que la problemática en torno a la ejecución de las penas limitativas de derechos consiste en que, a pesar de que éstas tienen varios años de vigencia, no han impactado a la ciudadanía. Indican, además, que en algunos casos ciertos magistrados prefieren imponer penas privativas de libertad en lugar de prestación de servicios comunitarios.

Respecto a las entidades, agregan Hurtado y Prado, esta vez citando a Vásquez, ${ }^{9}$ que reciben condenados a esta pena, que discriminan en cuanto a las plazas que proveen, aun cuando existen convenios suscritos con el INPE. Así, pese a que algunos sentenciados son profesionales, médicos, abogados, contadores, u otros, las plazas que se suministran normalmente son para actividades menores, como la limpieza de servicios públicos y baños, mantenimiento de jardines, faenas que estas personas son reacias a cumplir.

Finalmente, respecto a la pena de prestación de servicios a la comunidad, Hurtado y Prado $^{10}$ agregan que el futuro de la pena de prestación de servicios a la comunidad está asegurado en la legislación peruana, al darle mayor espacio conminatorio al excluir la pena privativa de libertad para delitos leves y autorizar su aplicación sustitutiva en casos de delitos de mediana gravedad (artículos 29, 31 y 53).

Para Hans Jescheck, citado por Villa Stein, ${ }^{11}$ consistiría esta pena en la prestación de determinadas horas de trabajo no remunerado y útil a la comunidad, prestado durante el tiempo libre.

Advierte Villa Stein, ${ }^{12}$ que no se trata de un trabajo forzado en favor a la comunidad. Se concreta en instituciones educativas y municipalidades, asistenciales o en obras públicas, en los que se deben tomar en cuenta las aptitudes y hasta las preferencias del sentenciado. Y precisa que la prestación se realiza preferentemente en días feriados, a fin de no alterar los patrones laborales del sentenciado, y la jornada de trabajo es de diez horas a la semana, y en ningún caso deberá afectar la

\footnotetext{
${ }^{9}$ Ibidem, p. 283.

${ }^{10}$ Idem.

${ }^{11}$ Villa Stein, Javier, Derecho penal. Parte general, Lima, Ara Editores, 2014, p. 558.

${ }^{12}$ Idem.
} 
Esta revista forma parte del acervo de la Biblioteca Jurídica Virtual del Instituto de Investigaciones Jurídicas de la UNAM

salud física o mental del obligado ni su dignidad personal; considera que esta opción punitiva, de organizarse debidamente, es muy superior al fácil recurso de suspender condicionalmente la ejecución de la pena, cayendo con ello en lo que Mantovani refiriéndose a la suspensión condicional de la pena, Ilama "clemencialismo".

\section{Organización y ejecución de la pena de prestación de servicios a la comunidad}

La organización y ejecución de las penas limitativas de derechos en el Perú, se encuentra establecida en los artículos 28, 31 al 35 y del 53 al 54 del Código Penal peruano, $^{13}$ y en los artículos 119 al 123 del Código de Ejecución Penal. ${ }^{14}$

La aplicación técnica de la prestación de servicios a la comunidad y limitación de días libres, se encuentra en la Ley de Ejecución de las Penas de Prestación de Servicios a la Comunidad y de Limitación de Días Libres; ${ }^{15}$ en los artículos 243 al 269 del Reglamento del Código de Ejecución Penal, ${ }^{16}$ y en la Ley que modifica artículos de la Ley Núm. 27030, Ley de Ejecución de las Penas de Prestación de Servicios a la Comunidad y de Limitación de días libres $^{17}$ y su Reglamento. ${ }^{18}$

Con la dación del reciente Decreto legislativo, ${ }^{19}$ que regula a la ejecución de las penas de prestación de servicios a la comunidad y de limitación de días libres, se ordena en su única disposición complementaria derogatoria, la derogación de la Ley 27030, Ley de Ejecución de las Penas de Prestación de Servicios a la Comunidad y de Limitación de Días, y su modificatoria Ley Núm. 27935, así como su reglamento, aprobado por Decreto Supremo Núm. 022-2003-JUS; empero, está pendiente su

\footnotetext{
${ }^{13}$ Código Penal, cit.

${ }^{14}$ Código de Ejecución Penal, Decreto Legislativo Núm. 654, Diario Oficial El Peruano, Lima, 2 de agosto de 1991.

15 Ley 27030 Ley de Ejecución de Penas de Servicios a la Comunidad y de Limitación de Días Libres, Diario Oficial El Peruano, Lima, promulgado el 18 de diciembre de 1998.

${ }^{16}$ Decreto Supremo 015-2003-JUS Aprueban el Reglamento del Código de Ejecución Penal, Diario Oficial El Peruano, Lima, 11 de septiembre de 2003.

${ }^{17}$ Ley 27935 Ley que modifica artículos de la Ley de Ejecución de las penas de Prestación de Servicios a la Comunidad y de Limitación de Días Libres, Diario Oficial El Peruano, Lima, 12 de febrero de 2003.

${ }^{18}$ Decreto Supremo Núm. 022-2003-JUS Aprueban reglamento para ejecución y supervisión de penas de prestación de servicios a la comunidad y de limitación de días libres a cargo de municipalidades y la PNP, Diario Oficial El Peruano, Lima, 7 de noviembre de 2003.
}

${ }^{19}$ Decreto Legislativo Núm. 1191, 21 de agosto de 2015. 
reglamentación y adecuación de directivas y procedimientos para su eficaz cumplimiento.

El proceso de ejecución de la pena de prestación de servicios a la comunidad inicia cuando el INPE recibe la copia certificada de sentencia emitida por el juez que tuvo a cargo el juzgamiento, quien a su vez notifica y deriva al sentenciado a la Dirección de Medio Libre, para su posterior entrevista, evaluación y ubicación laboral.

Sobre esta etapa, el novísimo Reglamento de la Pena de Prestación de Servicios a la Comunidad y Limitación de Días Libres precisa el deber del juez competente para impulsar el proceso, resolver los incidentes que se susciten durante la ejecución de las sanciones establecidas, realizar las comunicaciones dispuestas por ley y practicar las diligencias necesarias para su debido cumplimiento, controlar que la ejecución de la pena limitativa se encuentre dentro de los parámetros fijados en la sentencia condenatoria, revisar de oficio o a solicitud de parte el cumplimiento de la sentencia, mínimo cada dos meses.

La ubicación del sentenciado a prestación de servicios a la comunidad se realiza previa evaluación por el equipo multidisciplinario que determine el área donde el sentenciado podrá realizar la prestación de servicios comunitarios y previa comunicación al sentenciado de las diversas plazas, indicando la función y horario en que se debe realizar la prestación; teniendo en cuenta las aptitudes, ocupación u oficio, edad y estado de salud del sentenciado, así como su domicilio, a fin de que no perjudique su jornada normal de trabajo o estudio.

La Dirección de Medio Libre asigna a la entidad receptora, ${ }^{20}$ la actividad específica y el horario que deba cumplir el sentenciado, indicando la fecha de inicio. Presenta al sentenciado con un oficio que precise el número de jornadas de servicio impuestas en la sentencia, el horario y el área donde el sentenciado deberá cumplirla; entrega las planillas para el control de asistencia a los sentenciados.

La Dirección de Medio Libre de la Dirección Regional Lima debe informar mensualmente al juez de origen, sobre el cumplimiento de la pena impuesta, adjuntando el reporte de la entidad receptora en las planillas de control laboral debidamente llenadas y devueltas mensualmente a la Dirección de Medio Libre, y teniendo en cuenta los informes de las visitas realizadas al local donde el sentenciado

\footnotetext{
${ }^{20}$ Según lo establecido en el artículo 40. del Decreto Legislativo 1191, las entidades receptoras pasan a ser unidades beneficiarias.
} 
cumple servicios, emitido por el supervisor designado. El cumplimiento de la pena será puesto de conocimiento al juez de origen.

Se considera incumplimiento injustificado de la prestación de servicios a la comunidad la inasistencia o el abandono del trabajo; el rendimiento manifiestamente inferior en el centro laboral a pesar de requerimiento escrito y reiterado del responsable de la entidad receptora de servicios a la comunidad; la resistencia o incumplimiento reiterado y manifiesto de las instrucciones dadas por el responsable de la entidad receptora de servicios a la comunidad. Para que no se considere incumplimiento de la pena, el sentenciado puede justificar su inasistencia inclusive por dos días consecutivos o tres días alternados durante un mes.

La entidad receptora de servicios a la comunidad informará a la Dirección de Medio Libre del incumplimiento de la pena y dará cuenta del abandono del trabajo. El supervisor se encargará de hacer las verificaciones necesarias y notificará al sentenciado, bajo apercibimiento de dar cuenta al juez de la causa, para que dé las explicaciones necesarias de su conducta, en el plazo máximo de diez días hábiles.

\section{Entes operadores de la pena prestación de servicios a la comunidad}

De acuerdo con lo establecido en el texto único ordenado de la Ley Orgánica del Poder Judicial, ${ }^{21}$ la potestad de administrar justicia emana del pueblo y se ejerce por el Poder Judicial a través de sus órganos jerárquicos con sujeción a la Constitución y las leyes. No existe ni puede instituirse jurisdicción alguna independiente del Poder Judicial, con excepción de la arbitral y la militar. Tratándose de los procesos por faltas y delitos, éstos son conocidos principalmente por los juzgados penales, los juzgados mixtos y los juzgados de paz letrados; por lo cual son quienes deciden el tipo de pena a aplicar al procesado. El encargado de supervisar el funcionamiento de la pena impuesta, y revocar la misma ante su incumplimiento por parte del sentenciado, es el juez que conoció de la causa.

El Instituto Nacional Penitenciario -INPE-, como órgano rector del sistema penitenciario nacional, es el encargado de coordinar con las entidades asistenciales y otras instituciones similares para asignar la prestación de servicios; supervisar el cumplimiento de la pena y comunicar al juzgado que conoció de la causa del resultado de la ejecución de la pena.

Las entidades receptoras son las instituciones designadas por el Instituto Nacional Penitenciario; reciben a los sentenciados para que presten servicios comunitarios en

\footnotetext{
${ }^{21}$ Decreto Supremo núm. 017-93-JUS, 3 de junio de 1993.
} 
forma gratuita, trabajo realizado en cumplimiento de la pena impuesta. A julio de 2012, el INPE cuenta con 1557 entidades receptoras a nivel nacional, correspondiendo a la Dirección de Medio Libre de la Dirección Regional Lima 423 entidades receptoras.

Tabla 1. Entidades receptoras a nivel nacional ${ }^{22}$

\begin{tabular}{|c|c|c|c|c|c|c|c|}
\hline \multirow[b]{2}{*}{$\begin{array}{l}\text { Oficinas } \\
\text { regionales }\end{array}$} & \multicolumn{6}{|c|}{ Entidades receptoras } & \multirow[b]{2}{*}{$\begin{array}{c}\text { Total } \\
\text { gene- } \\
\text { ral }\end{array}$} \\
\hline & $\begin{array}{c}\text { Instituciones } \\
\text { educativos }\end{array}$ & Parroquias & $\begin{array}{c}\text { Municipali- } \\
\text { dades }\end{array}$ & $\begin{array}{c}\text { Hospitales/ } \\
\text { centros de } \\
\text { salud }\end{array}$ & Comisarías & Otras & \\
\hline O. R. Norte- & & & & & & & \\
\hline Chiclayo & 268 & 17 & 71 & 36 & 40 & 213 & 645 \\
\hline O. R. Lima & 155 & 57 & 80 & 15 & 35 & 81 & 423 \\
\hline $\begin{array}{l}\text { O. R. Sur- } \\
\text { Arequipa }\end{array}$ & 40 & 14 & 36 & 5 & 4 & 22 & 121 \\
\hline $\begin{array}{l}\text { O. R. } \\
\text { Centro- } \\
\text { Huancayo }\end{array}$ & 7 & 0 & 17 & 2 & 2 & 9 & 37 \\
\hline $\begin{array}{l}\text { O. R. Nor } \\
\text { oriente-san } \\
\text { Martín }\end{array}$ & 20 & 3 & 25 & 9 & 1 & 2 & 61 \\
\hline $\begin{array}{l}\text { O. R. Sur } \\
\text { oriente- } \\
\text { Cusco }\end{array}$ & 20 & 1 & 23 & 8 & 5 & 22 & 79 \\
\hline $\begin{array}{l}\text { O. R. } \\
\text { Oriente- } \\
\text { Pucallpa }\end{array}$ & 73 & 3 & 21 & 18 & 1 & 44 & 160 \\
\hline $\begin{array}{l}\text { O. R. } \\
\text { Altiplano- } \\
\text { Puno }\end{array}$ & 21 & 0 & 3 & 2 & 1 & 4 & 31 \\
\hline Total & 604 & 95 & 276 & 95 & 89 & 398 & 1557 \\
\hline
\end{tabular}

${ }^{22}$ Dirección del Medio Libre, Instituto Nacional Penitenciario, Entidades receptoras a nivel nacional, julio de 2012, http://Www.inpe.gob.pe/contenidos. php?id=629\&np=35\&direccion=1. 


\begin{tabular}{|l|l|l|l|l|l|l|l|}
\hline general & & & & & & & \\
\hline
\end{tabular}

Otras instituciones: tenencia de gobernación, comités vaso de leche, comedores populares, compañía de bomberos, beneficencia, guarderías, etcétera.

Fuente: Oficinas regionales-establecimientos de Ejecución de Penas Limitativas de Derechos.

\section{Elaboración: INPE-Dirección de Medio Libre}

Es de mencionar que el Decreto Legislativo 1191 dispone la ejecutabilidad de las sentencias y la tutela efectiva al juez competente; es decir, aquel que tuvo a cargo el juzgamiento del penado, contando con las medidas coercitivas que la ley le otorga para dicho fin, concretizando la tutela efectiva del requerimiento que originó el proceso y, con ello, el cumplimiento de la Constitución Política del Perú y las leyes correspondientes.

Fija que la entidad responsable de la supervisión de las penas limitativas de derechos es el Instituto Nacional Penitenciario, a través de la Dirección de Medio Libre, sus órganos desconcentrados o los que hagan sus veces.

Define como unidades beneficiarias a toda institución pública, registrada ante la Dirección de Medio Libre, sus órganos desconcentrados o los que hagan sus veces, que brinde servicios asistenciales, como los de salud, educación u otros servicios similares, que dependan del gobierno nacional, regional, local o de organismos autónomos. También pueden ser consideradas unidades beneficiarias, aquellas instituciones privadas sin fines de lucro que brinden servicios asistenciales o sociales.

\section{Acerca del cumplimiento de la pena de prestación de servicios a la comunidad}

A pesar de las bondades de la pena de prestación de servicios a la comunidad, más del 50\% de sentenciados la incumple, desconociéndose sus causas; al respecto, surgiendo la interrogante de si el cumplimiento de la pena está relacionado con el cumplimiento del proceso normado para su ejecución.

La autora determinó en una investigación previa que en una población de 2,070 sentenciados a prestación de servicios a la comunidad, utilizando el diseño no experimental de corte transversal, que una proporción menor a 0.50 de sentenciados ha cumplido la pena de prestación de servicios a la comunidad, y que existe una mayor proporción de mujeres que cumplen con las penas respecto de los varones, 
Esta revista forma parte del acervo de la Biblioteca Jurídica Virtual del Instituto de Investigaciones Jurídicas de la UNAM

aunque la asociación entre el cumplimiento y el género no es significativa $(r=0.23) .^{23}$ Los índices de cumplimiento de estas penas en los establecimientos de provincia son más altos que en Lima metropolitana y Callao; la asociación encontrada entre ambas variables es media (4=0.57). En un segundo segmento poblacional de 1,237 sentenciados, analiza la variable cumplimiento en relación con las variables delito o falta y número de jornadas de sentencia, encontrándose una ligera proporcionalidad favorable de cumplimientos en delitos contra la familia, contra la administración pública y contra la fe pública; no se encontró relación entre el número de jornadas de sentencias y el cumplimiento de la pena.

Ramos, ${ }^{24}$ en un estudio descriptivo realizado en Lima, reconoce que las penas limitativas de derechos son propuestas alternativas de gran alcance contempladas en el ordenamiento jurídico penal peruano, y señala que en la observación realizada a los penados en el medio libre donde prestan servicios, se ha encontrado a profesionales abogados, profesores y contadores, trabajando en áreas distintas.

Según el estudio realizado por la Defensoría del Pueblo, sólo el $12 \%$ de sentenciados a penas de prestación de servicios comunitarios habría cumplido la ejecución de la pena impuesta. ${ }^{25}$

En 1993, el Instituto Brasileiro de Ciencias Criminais (IBCCrim) encontró en la ciudad de Porto Alegre, Brasil, que $12.54 \%$ de los condenados a la prestación de servicios a la comunidad volvieron a delinquir; esto frente al promedio de $47 \%$ sentenciados reincidentes en las penas privativas de libertad.

García, P. (1998) ${ }^{26}$ encontró que según información de la Consejería de Educación y Cultura de la comunidad de Madrid, de las 24 sentencias dictadas desde la entrada en

\footnotetext{
${ }^{23}$ Riega-Viru, Yasmina, Penas limitativas de derechos en el Perú, tesis para optar el grado académico de maestra en derecho penal, Universidad Nacional Federico Villarreal, Lima, 2004, p. 5.

${ }^{24}$ Ramos Suyo, Juan, Manual de excarcelación ciencia penitenciaria, Lima, Editora FECAT, 2000.

25 Defensoría del Pueblo, Justicia de paz letrada en comisarías: una propuesta para enfrentar la inseguridad ciudadana, Serie de Informes Defensoriales-Informe núm. 119, Lima, Adjuntía en Asuntos Constitucionales, 2007, p. 61. http://WWW2.congreso.gob.pe/sicr/cendocbib/con4_uibd.nsf/3D71BD30C7E85EF905257CBC0057D3B6/\$F ILE/1_pdfsam_informe_119.pdf.

${ }^{26}$ García Valdez, Carlos, Alternativas legales a la privación de la libertad clásica, en prevención y teoría de la pena, Santiago de Chile, Editorial Jurídica Cono Sur, 1995, pp. 197 y ss.
} 
vigencia del nuevo Código Penal, en 1995, sólo nueve sentenciados habrían cumplido la pena de prestación de servicios comunitarios, en la comunidad de Madrid.

El propósito del estudio fue dar a conocer el estado real de la aplicación de la pena limitativa de derechos, por considerarse que es la verdadera alternativa a la pena privativa de libertad, pues por un lado cumple con el principio resocializador contemplado en el artículo 139 de la Constitución Política del Perú, ${ }^{27}$ y por otro, los fines de prevención y protección a la sociedad.

Se estableció como objetivo determinar si existe relación entre el cumplimiento de las disposiciones normativas por parte de los actores de la ejecución de las sentencias a prestación de servicios a la comunidad y el cumplimiento de la pena por parte de los sentenciados de los establecimientos de asistencia pospenitenciaria y de ejecución de penas limitativas de derechos de la Oficina Regional Lima del Instituto Nacional Penitenciario periodo 2007.

\section{METODOLOGÍA}

Estudio descriptivo correlacional transversal que pertenece al área socio-jurídico. Se inició como un estudio descriptivo y luego correlacional. El método utilizado es el inductivo-deductivo de manera general, y el analítico - interpretativo a partir del análisis estadístico.

La población de estudio estuvo conformada por 738 sentenciados a penas limitativas de derechos en su modalidad de prestación de servicios a la comunidad, con expedientes ingresados al año $2007^{28}$ en los establecimientos de medio libre y ejecución de penas limitativas de derechos de Huacho, Zárate, Surquillo e Independencia de Lima metropolitana, y el establecimiento de medio libre y ejecución de penas limitativas de derechos de la provincia constitucional del Callao. Para la determinación de la muestra se aplicó un muestreo aleatorio simple con un nivel de confianza de $95 \%$ y una variabilidad de 0.5 y un margen de error del 0.05 , quedando 150 sentenciados (véase tabla núm. 2), a los cuales se les aplicaron criterios de inclusión y exclusión. Se seleccionaron sentenciados que estén cumpliendo y que habían concluido la pena de prestación de servicios a la comunidad, y se indagó sobre el cumplimiento de las normas y leyes por parte de las autoridades

\footnotetext{
${ }^{27}$ Rubio Correa, Marcial, Para conocer la Constitución de 1993, 2a. ed., Lima, Fondo Editorial Pontificia Universidad Católica del Perú, 2008, p. 228.

${ }^{28}$ Se consideró el total de expedientes en proceso de cumplimiento al año 2007, incluye los años anteriores. El tiempo máximo de la pena es de cuatro años.
} 
de los establecimientos de ejecución del INPE y las entidades receptoras; se procedió de igual manera con sentenciados que habían cumplido como con los que no habían cumplido con la pena de prestación de servicios a la comunidad impuesta.

La información necesaria para ^l desarrollo de la investigación se recopiló mediante las técnicas de análisis docurnentario y escala tipo Likert.

El análisis documentario se usó para medir el cumplimiento del proceso normado por parte de los establecimientos de asistencia pospenitenciaria y de ejecución de penas limitativas de derechos y de las entidades receptoras; es decir, se hizo una lectura, revisión y análisis de los expedientes personales de cada sentenciado informante de la muestra.

Para medir la actitud de los sentenciados frente a la sentencia se utilizó una escala de Likert, la cual fue aplicada a cada liberado en forma personalizada en su respectivo domicilio. Esta escala arrojó resultados de tipo categórico, como: muy desfavorable, desfavorable, favorable y muy favorable. La validez de esa escala se determinó mediante criterio de jueces. En esta validación participaron diez profesionales del Instituto Nacional Penitenciario como jueces; todos ellos tuvieron una calificación de buena para los ítems, y la correlación inter jueces fue de 0.80 .

Para presentar los resultados se hizo uso de estadísticos descriptivos, como la frecuencia, proporciones y tablas de contingencia; asimismo, se utilizó la estadística inferencial no paramétrica Chi cuadrada de Pearson $\left(\mathrm{X}^{2}\right)$ para determinar la posible asociación entre las variables estudiadas. $Y$ de $V$ de Cramer y coeficiente de contingencia, la tabla superó el modelo $2 \times 2$, y considerando la existencia de celdas con valores iguales a 0 , se optó por complementar el índice de asociación mediante los estadísticos coeficiente de contingencia y V de Cramer.

Tabla 2. Muestra de sentenciados con penas de prestación de servicios a la comunidad según EML y EPLD 


\begin{tabular}{lll} 
EAPP y EPLD & FRECUENCIA & $\%$ \\
\hline Huacho & 20 & $13 \%$ \\
Zárate & 40 & $27 \%$ \\
Surquillo & 17 & $11 \%$ \\
Independencia & 52 & $35 \%$ \\
Callao & 21 & $14 \%$ \\
\hline \hline Total & 150 & $100 \%$
\end{tabular}

\section{RESULTADOS}

\section{Cumplimiento de las disposiciones normativas por parte}

de las entidades receptoras

Contrastando el cumplimiento por parte de la entidad receptora, de comunicar a la Dirección de Medio Libre del INPE sobre la ejecución de la sentencia a prestación de servicios a la comunidad, se tiene que el $77 \%$ de las entidades receptoras estudiadas incumplen la disposición de devolver las planillas de control laboral de los sentenciados, debidamente llenadas; el 23\% cumple dicha disposición.

Tabla 3. Sentenciados por ejecución de sentencia, según cumplimiento de entidad receptora de devolver al INPE las planillas de control laboral debidamente llenadas. 


\begin{tabular}{|c|c|c|c|c|c|}
\hline \multirow{2}{*}{\multicolumn{2}{|c|}{ ENTIDAD RECEPTORA }} & \multicolumn{2}{|c|}{ EJECUCIÓN DE SENTENCIA } & \multicolumn{2}{|c|}{ TOTAL } \\
\hline & & NO CUMPLE & CUMPLE & FR. & $\%$ \\
\hline \multirow{2}{*}{$\begin{array}{l}\text { No } \\
\text { cumple }\end{array}$} & Fr. observada & 86 & 29 & 115 & $77 \%$ \\
\hline & Fr. esperada & 69 & 46 & 115 & \\
\hline \multirow{2}{*}{ Cumple } & Fr. observada & 4 & 31 & 35 & $23 \%$ \\
\hline & Fr. esperada & 21 & 14 & 35 & \\
\hline \multicolumn{2}{|l|}{ Total } & 90 & 60 & 150 & $100 \%$ \\
\hline
\end{tabular}

Aplicando el estadístico Chi cuadrada de Pearson $\left(X^{2}\right)$, para las variables señaladas en la tabla núm. 4; es decir, cumplimiento o no cumplimiento de la disposición referida en el artículo 263 del D.S. Núm. 015-2003-JUS-Reglamento el Código de Ejecución Penal, y el artículo 13, inciso 13.2, de la Ley Núm. 27030-Ley de Ejecución de las Penas de Prestación de Servicios a la Comunidad y de limitación de días libres, y por otro lado, el cumplimiento o incumplimiento de la sentencia por parte de los sentenciados a prestación de servicios a la comunidad, se tiene un valor $X^{2}$ de 44.88 , con un grado de libertad de uno y un nivel de significancia de 0.000 , lo que significa que ambas variables se encuentran relacionadas.

Este incumplimiento genera que no se pueda controlar de manera continua a los sentenciados, lo cual incide en los abandonos del cumplimiento de la sentencia de prestación de servicios gratuitos a la comunidad, como lo demuestra el nivel significancia de 0.00 para el estadístico Chi cuadrada $\left(X^{2}\right)$ entre cumplimiento de la remisión mensual de las planillas de control laboral de los sentenciados, debidamente llenadas por parte de las entidades receptoras, y el cumplimiento de la sentencia.

Al investigar si la entidad receptora asigna labores específicas por jornada a los sentenciados de prestación de servicios a la comunidad, en las jurisdicciones de la Dirección de Medio Libre de la Dirección Regional Lima del Instituto Nacional Penitenciario, se encontró que $46 \%$ de las entidades receptoras no cumple con 
asignar tareas específicas para cada jornada de prestación de servicios a la comunidad de los sentenciados; sólo el 54\% cumple este requerimiento.

Tabla 4. Sentenciados por ejecución de sentencia, según cumplimiento de entidad receptora de asignar tareas para cada jornada.

\begin{tabular}{|c|c|c|c|c|c|}
\hline \multirow{2}{*}{\multicolumn{2}{|c|}{ ENTIDAD RECEPTORA }} & \multicolumn{2}{|c|}{ EJECUCIÓN DE SENTENCIA } & \multicolumn{2}{|c|}{ TOTAL } \\
\hline & & NO CUMPLE & CUMPLE & FR. & $\%$ \\
\hline \multirow{2}{*}{ No cumple } & Fr. observada & 54 & 15 & 69 & $46 \%$ \\
\hline & Fr. esperada & 41 & 28 & 69 & \\
\hline \multirow{2}{*}{ Cumple } & Fr. observada & 36 & 45 & 81 & $54 \%$ \\
\hline & Fr. esperada & 49 & 32 & 81 & \\
\hline \multicolumn{2}{|l|}{ Total } & 90 & 60 & 150 & $100 \%$ \\
\hline
\end{tabular}

Aplicando el estadístico Chi cuadrada de Pearson $\left(X^{2}\right)$, para determinar la posible asociación entre cumplimiento de sentencias a prestación de servicios a la comunidad por parte de los penados y cumplimiento de las entidades receptoras de asignar tareas específicas a los sentenciados para cada jornada de trabajo, se encontró un valor $X^{2}$ de 17.75 , para un grado de libertad de uno en una tabla de contingencia de $2 \times 2$, y una significancia asintónica bilateral de 0,000. Nivel de significancia que indicaría estadísticamente que ambas variables se encuentran relacionadas.

Verificando si las entidades receptoras designan un responsable para controlar el trabajo del sentenciado a prestación de servicios a la comunidad, en las jurisdicciones de los establecimientos de medio libre y de ejecución de penas limitativas de derechos, de la Dirección Regional Lima del Instituto Nacional Penitenciario, se encontró que $84 \%$ de entidades receptoras no designan responsable para el control minucioso de la prestación de servicios de los sentenciados; mientras que sólo 16\% de entidades designan personal responsable para esta labor.

Haciendo uso del estadístico para variables nominales, Chi cuadrada de Pearson $\left(X^{2}\right)$, a fin de determinar la existencia de asociación entre cumplimiento de sentencias a prestación de servicios a la comunidad por parte de los penados y la designación por parte de la entidad receptora, de un personal responsable del control de las 
jornadas de prestación de servicios a la comunidad, se encontró un valor $\mathrm{X}^{2}$ de 26.86 , con un grado de libertad de uno en una tabla de contingencia de 2x2; y un nivel de significancia asintónica bilateral de 0.000. Significancia que estaría indicando que ambas variables se encuentran estadísticamente relacionadas.

\section{Cumplimiento de las disposiciones normativas por parte de la Dirección} de Medio Libre de la Dirección Regional Lima

Luego de una revisión minuciosa de los procedimientos en los establecimientos de ejecución de penas limitativas de derechos y de los expedientes, se investigó si los establecimientos cumplían con la ubicación del sentenciado a la entidad receptora determinando estrictamente la fecha de inicio de jornadas; se encontró que 32\% de establecimientos incumple esta precisión, el 68\% sí cumple con este dispositivo, lo que significa que en $32 \%$ de casos el sistema se muestra demasiado flexible, otorgando al sentenciado la libertad de iniciar las jornadas a su libre albedrío, situación que perjudica el rigor de la sentencia y el cumplimiento de la misma, máxime si se tiene en cuenta que luego de aplicar un estadístico de asociación resulta que existe una asociación significativa entre la determinación exacta y estricta de la fecha de inicio de jornadas laborales y el cumplimiento de la sentencia.

Al investigar si la Dirección de Medio Libre de la Oficina Regional Lima del Instituto Nacional Penitenciario cumple con ubicar laboralmente al sentenciado en una entidad receptora cercana a su domicilio, se encontró que en $49 \%$ de los casos no se cumple esta disposición, mientras que en $51 \%$ de los casos esta disposición se cumple.

Aplicando el estadístico Chi cuadrada de Pearson $\left(\mathrm{X}^{2}\right)$, para determinar la posible asociación entre cumplimiento de sentencias a prestación de servicios a la comunidad por parte de los penados y el cumplimiento del equipo multidisciplinario de la Dirección de Medio Libre, de ubicar laboralmente al sentenciado en entidad receptora cercana a su casa, se encontró un valor $X^{2}$ de 19.37 , para un grado de libertad de uno en una tabla de contingencia de 2×2; y una significancia asintónica bilateral de 0.000 . Nivel de significancia que indicaría estadísticamente que ambas variables se encuentran relacionadas.

Al verificar la asignación de trabajos comunitarios en la entidad receptora de acuerdo con las habilidades del sentenciado en la Dirección de Medio Libre de la Oficina Regional Lima del Instituto Nacional Penitenciario, se tiene que en $69 \%$ de los casos estudiados no se cumple esta disposición, mientras que en $31 \%$ de los casos restantes esta disposición se cumple. 
Esta revista forma parte del acervo de la Biblioteca Jurídica Virtual del Instituto de Investigaciones Jurídicas de la UNAM

Tabla 5. Ejecución de sentencia, según cumplimiento de ubicación de sentenciado de acuerdo con sus aptitudes

\begin{tabular}{|c|c|c|c|c|c|}
\hline \multirow{2}{*}{ EML Y EPPLD } & & \multicolumn{2}{|c|}{ EJECUCIÓN DE SENTENCIA } & \multicolumn{2}{|c|}{ TOTAL } \\
\hline & & NO CUMPLE & CUMPLE & FR. & $\%$ \\
\hline \multirow{2}{*}{ No cumple } & Fr. observada & 74 & 30 & 104 & $69 \%$ \\
\hline & Fr. esperada & 62 & 42 & 104 & \\
\hline \multirow{2}{*}{ Cumple } & Fr. observada & 16 & 30 & 46 & $31 \%$ \\
\hline & Fr. esperada & 28 & 18 & 46 & \\
\hline Total & & 90 & 60 & 150 & $100 \%$ \\
\hline
\end{tabular}

Aplicando el estadístico Chi cuadrada de Pearson $\left(X^{2}\right)$ para determinar la posible asociación entre cumplimiento de sentencias a prestación de servicios a la comunidad por parte de los penados y el cumplimiento del equipo multidisciplinario de la Dirección de Medio Libre, de ubicar laboralmente al sentenciado en la entidad receptora tomando en cuenta las aptitudes del mismo, se encontró un valor $X^{2}$ de 17.58, para un grado de libertad de uno en una tabla de contingencia de $2 \times 2$, y una significancia asintónica bilateral de 0.000. Nivel de significancia que indicaría estadísticamente que ambas variables se encuentran relacionadas.

En lo que respecta a la asignación de labores específicas a ejecutar por jornada en la entidad receptora, esta acción se hace necesaria a fin de que el sentenciado tenga funciones reales a desempeñar en la prestación de servicios a la comunidad. El artículo 11 de la Ley Núm. 27030 (Ley de Ejecución de las Penas de Prestación de Servicios a la Comunidad y de Limitación de Días Libres) dispone que el jefe del órgano técnico se coordinará con las entidades receptoras para ubicar a los sentenciados de acuerdo con sus aptitudes.

Esta ubicación requiere que la entidad receptora, de manera previa, haga llegar una relación de los puestos y labores disponibles en la entidad, a los profesionales del órgano técnico de la Dirección de Medio Libre, a fin de que cuando sea designado el sentenciado se le señalen las funciones específicas que desempeñará en cada jornada.

El artículo 120 del Código de Ejecución Penal y el artículo 256 de su Reglamento 
señalan que para la evaluación de ubicación laboral del sentenciado, en una entidad receptora, los profesionales del equipo multidisciplinario de la Dirección de Medio Libre deben tomar en cuenta, entre otros factores, el lugar de domicilio del penado, de manera que no perjudique su jornada normal de trabajo o estudio.

Esta disposición permite al sentenciado no verse perjudicado en cuanto a tiempo, ocupación laboral y cuidado familiar, ya que al ejecutarse la sentencia de prestación de servicios a la comunidad en un lugar cercano a su domicilio, aumenta la probabilidad de cumplimiento de la misma.

Se constató la relación significativa entre el cumplimiento de la sentencia y la ubicación laboral en una entidad receptora cercana al domicilio del penado; lastimosamente, sólo en $51 \%$ este dispositivo se cumple, y en $49 \%$ de los casos estudiados la Dirección de Medio Libre de la Dirección Regional Lima del Instituto Nacional Penitenciario no toma en cuenta esta variable, situación que contribuye con la ineficacia de la pena de prestación de servicios a la comunidad.

Al verificar si los establecimientos de medio libre y de ejecución de penas limitativas de derechos, de la Oficina Regional Lima del Instituto Nacional Penitenciario, en el acto de la ubicación laboral del sentenciado, determinan y señalan la fecha estricta de inicio de sentencia, se encontró que $32 \%$ de los casos de los establecimientos incumple esta disposición; es decir, no determina la fecha exacta de inicio de las jornadas laborales por parte del sentenciado; mientras que el 68\% restante de los casos sí cumple con este dispositivo.

Haciendo uso del estadístico Chi cuadrada de Pearson $\left(X^{2}\right)$, a fin de determinar la existencia de asociación entre cumplimiento de sentencias a prestación de servicios a la comunidad por parte de los penados y la ubicación de sentenciado determinando estricta fecha de inicio de jornadas de prestación de servicios, se encontró un valor $X^{2}$ de 16.05 , con un grado de libertad de uno en una tabla de contingencia de $2 \times 2$, y un nivel de significancia asintónica bilateral de 0.000 . Significancia que estaría indicando que ambas variables se encuentran estadísticamente relacionadas.

Al investigar si la Dirección de Medio Libre de la Oficina Regional Lima cumple con remitir oportunamente las planillas de control a entidades receptoras, se encontró que en $43 \%$ de los casos estudiados no se cumple esta disposición, mientras que el 57\% de los casos restantes sí cumple esta disposición.

Al determinar la posible asociación entre cumplimiento de sentencias a prestación de servicios a la comunidad por parte de los penados y el cumplimiento de remisión 
de planillas de control laboral a las entidades receptoras por la Dirección de Medio Libre, mediante el estadístico Chi cuadrada de Pearson $\left(\mathrm{X}^{2}\right)$, se encontró un valor $\mathrm{X}^{2}$ de 31.29 , para un grado de libertad de uno en una tabla de contingencia de $2 \times 2$, y una significancia asintónica bilateral de 0.000. Nivel de significancia que indicaría estadísticamente que ambas variables se encuentran relacionadas.

La remisión de planillas a la entidad receptora le permite a esta última contar con instrumentos de control laboral de los sentenciados; la no remisión de esta documentación muestra descuido y ausencia de interés por parte de quienes son los encargados del control de la ejecución de la sentencia, y extiende el plazo para dar inicio a la ejecución de la prestación de servicios. Ello se infiere de la asociación significativa encontrada entre la remisión oportuna de planillas de control a entidades receptoras y la eficacia de la sentencia. Lastimosamente, aún existe $43 \%$ de casos en los que no se cumple esta disposición.

Al verificar si la Dirección de Medio Libre de la Dirección Regional Lima del Instituto Nacional Penitenciario, a través de su personal, cumple con supervisar mensualmente a los sentenciados en las entidades receptoras, se encontró que en $70 \%$ de los casos se incumple esta disposición; es decir, no se supervisa ni se comunica al juez mensualmente sobre el trabajo del sentenciado en las entidades receptoras, mientras que el 30\% restante de los casos sí cumple con este dispositivo.

Al determinar la posible asociación entre cumplimiento de sentencias a prestación de servicios a la comunidad por parte de los penados y el cumplimiento de la supervisión del servicio comunitario por parte de los supervisores de la Dirección de Medio Libre, en la entidad receptora; mediante el estadístico Chi cuadrada de Pearson $\left(X^{2}\right)$, se encontró un valor $X^{2}$ de 42.86 , para un grado de libertad de uno en una tabla de contingencia de $2 \times 2$; y una significancia asintónica bilateral de 0.000 . Nivel de significancia que indicaría estadísticamente que ambas variables se encuentran relacionadas.

La supervisión mensual de sentenciados en las entidades receptoras guarda una relación estadística significativa con el cumplimiento de la sentencia; esto debido a que el control permanente sobre el sentenciado permite mantener un seguimiento oportuno de la ejecución de la sentencia, y permite realizar acciones de control y acciones correctivas frente a la irresponsabilidad y resistencia del sentenciado al cumplimiento de la sentencia judicial. Sin embargo, se observa que en $70 \%$ de los casos, los establecimientos incumplen esta disposición, situación que se suma y concurre con la ineficacia de la penas de prestación de servicios a la comunidad. 
La Dirección de Medio Libre de la Dirección Regional Lima, al no supervisar mensualmente a los sentenciados en las entidades receptoras, tampoco comunica al juez mensualmente ni notifica oportunamente al sentenciado ante su inasistencia a la entidad receptora; por ello se encontró que en $61 \%$ de los casos no cumple con notificar al sentenciado ante su inasistencia al cumplimiento de las jornadas, mientras que el 39\% restante de los casos sí cumple con este dispositivo.

Tabla 6. Ejecución de sentencia en los EML y EPPLD, según cumplimiento de notificación del sentenciado frente a incumplimiento

\begin{tabular}{|c|c|c|c|c|c|}
\hline \multirow{2}{*}{ EML Y EPPLD } & & \multicolumn{2}{|c|}{ EJECUCIÓN DE SENTENCIA } & \multicolumn{2}{|c|}{ TOTAL } \\
\hline & & NO CUMPLE & CUMPLE & FR. & $\%$ \\
\hline \multirow{2}{*}{ No cumple } & Fr. observada & 67 & 24 & 91 & $61 \%$ \\
\hline & Fr. esperada & 55 & 36 & 91 & \\
\hline \multirow{2}{*}{ Cumple } & Fr. observada & 23 & 36 & 59 & $39 \%$ \\
\hline & Fr. esperada & 35 & 24 & 59 & \\
\hline Total & & 90 & 60 & 150 & $100 \%$ \\
\hline
\end{tabular}

Al aplicar el estadístico Chi cuadrada de Pearson $\left(X^{2}\right)$, para determinar la posible asociación entre cumplimiento de sentencias a prestación de servicios a la comunidad por parte de los penados y el cumplimiento por parte de la Dirección de Medio Libre, de notificar al sentenciado ante inasistencia injustificada a la entidad receptora, se encontró un valor $X^{2}$ de 17.90, para un grado de libertad de uno en una tabla de contingencia de 2×2; y una significancia asintónica bilateral de 0.000 . Nivel de significancia que indicaría estadísticamente que ambas variables se encuentran relacionadas.

En cumplimiento a lo establecido en el artículo 267 del Reglamento del Código de Ejecución Penal y el artículo 9, literal d3), de la Ley 27030 (Ley de Ejecución de las Penas de Prestación de Servicios a la Comunidad y de Limitación de Días Libres), la Dirección de Medio Libre debe primero notificar al sentenciado a efectos de que justifique su inasistencia a prestar el cumplimiento de la prestación de servicios a la comunidad como procedimiento previo del informe al juez de origen; sin embargo, se aprecia que en el $61 \%$ de los casos la Dirección de Medio Libre no cumple 
Esta revista forma parte del acervo de la Biblioteca Jurídica Virtual del Instituto de Investigaciones Jurídicas de la UNAM

oportunamente esta acción, debido a que la detección de inasistencia e incumplimientos de la sentencia se da de manera inoportuna, y con excesivo tiempo de retraso. Esta deficiencia trae consigo que las sentencias prescriban antes de que se comunique a la autoridad judicial el incumplimiento.

Si se toma en cuenta que la acción de notificar al sentenciado oportunamente se relaciona significativamente con el cumplimiento o incumplimiento de la sentencia, se puede inferir que mediante esta inacción se contribuye a incrementar la ineficacia que viene demostrando la ejecución de la pena de prestación de servicios a la comunidad.

\section{Actitud de los penados con sentencias a prestación de servicios} comunitarios y el cumplimiento de sus sentencias

De acuerdo con la actitud que presentan los sentenciados a prestación de servicios a la comunidad, de la Dirección de Medio Libre de la Oficina Regional Lima, respecto a la pena de prestación de servicios a la comunidad con la que fueron sancionados, se tiene que $2 \%$ presenta una actitud muy desfavorable hacia la sentencia; $35 \%$ presenta una actitud desfavorable; un porcentaje similar, es decir, 35\%, presenta una actitud favorable hacia su sentencia; mientras que el $28 \%$ restante presenta una actitud muy favorable hacia la sentencia recibida.

Tabla 7. Ejecución de sentencia en los EML y EPPLD, según actitud de los sentenciados hacia la pena

\begin{tabular}{|c|c|c|c|c|c|}
\hline \multirow{2}{*}{\multicolumn{2}{|c|}{ ACTITUD DEL SENTENCIADO }} & \multicolumn{2}{|c|}{ EJECUCIÓN DE SENTENCIA } & \multicolumn{2}{|c|}{ TOTAL } \\
\hline & & NO CUMPLE & CUMPLE & FR. & $\%$ \\
\hline \multirow{2}{*}{ Muy desfavorable } & Fr. observada & 3 & 0 & 3 & $2 \%$ \\
\hline & Fr. esperada & 1.8 & 1.2 & 3 & \\
\hline \multirow{2}{*}{ Desfavorable } & Fr. observada & 47 & 6 & 53 & $35 \%$ \\
\hline & Fr. esperada & 31.8 & 21.2 & 53 & \\
\hline \multirow{2}{*}{ Favorable } & Fr. observada & 39 & 13 & 52 & $35 \%$ \\
\hline & Fr. esperada & 31.2 & 20.8 & 52 & \\
\hline \multirow{2}{*}{ Muy favorable } & Fr. observada & 1 & 41 & 42 & $28 \%$ \\
\hline & Fr. esperada & 25.2 & 16.8 & 42 & \\
\hline \multicolumn{2}{|l|}{ Total } & 90 & 60 & 150 & $100 \%$ \\
\hline
\end{tabular}




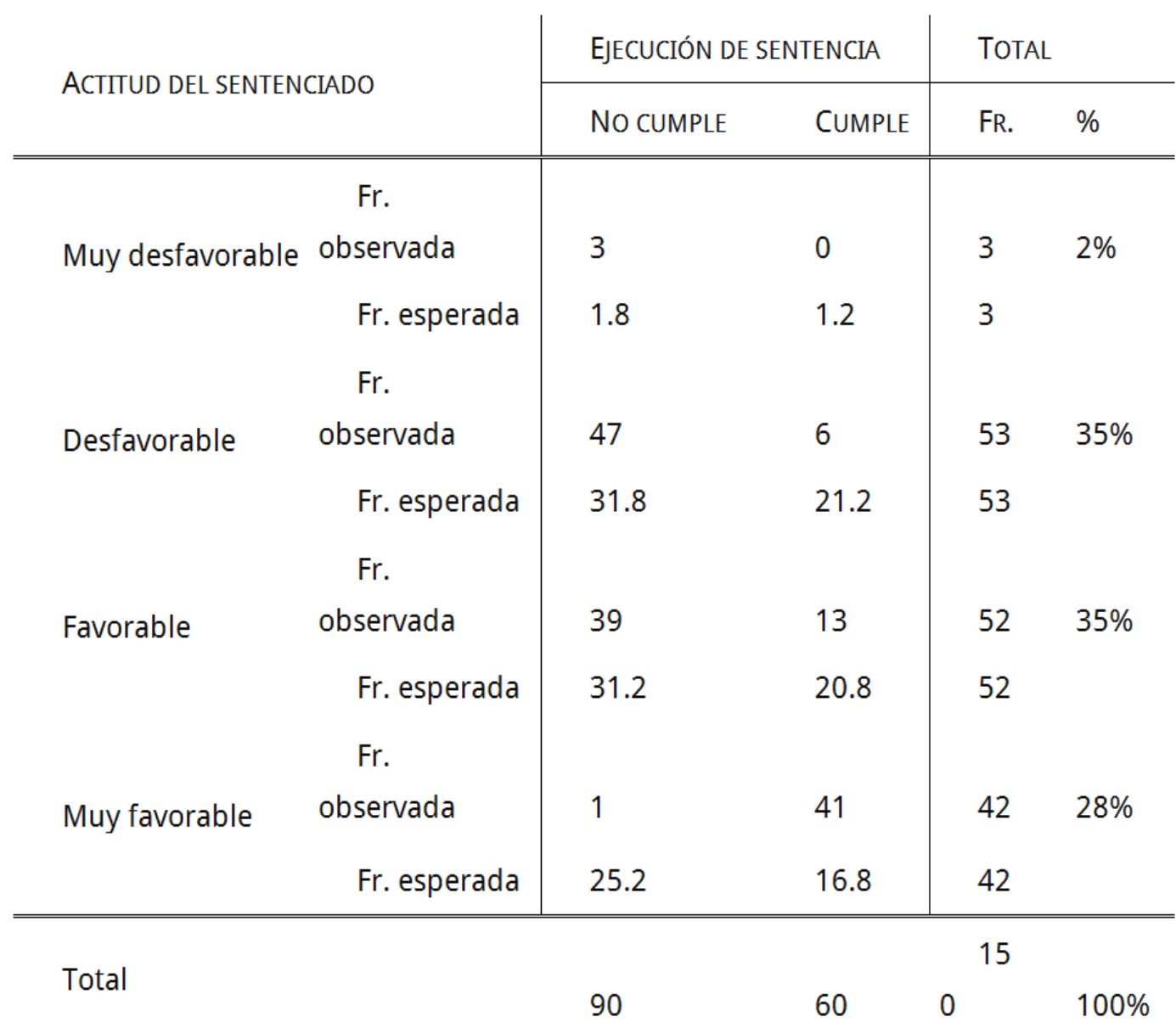

Al aplicar el estadístico Chi cuadrada de Pearson $\left(X^{2}\right)$, para determinar la posible asociación entre cumplimiento de sentencias a prestación de servicios a la comunidad por parte de los penados y la actitud hacia la sentencia de prestación de servicios a la comunidad recibida por la autoridad jurisdiccional, se encontró un valor $\mathrm{X}^{2}$ de 83.14, para un grado de libertad de tres en una tabla de contingencia de $4 \times 2$; y una significancia asintónica bilateral de 0.000. Nivel de significancia que indicaría estadísticamente que ambas variables se encuentran relacionadas.

Tabla 8. Coeficiente de relación entre el cumplimiento de la pena y la actitud de los sentenciados hacia la pena $\left(\mathrm{X}^{2}\right)$ 
Esta revista forma parte del acervo de la Biblioteca Jurídica Virtual del Instituto de Investigaciones Jurídicas de la UNAM

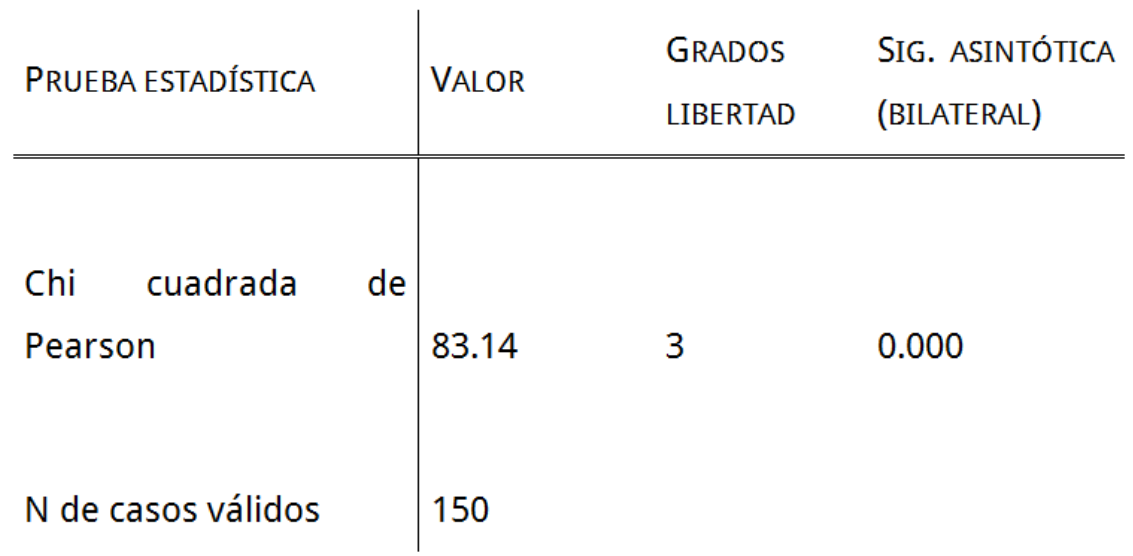

Dado que la tabla supera el modelo $2 \times 2$, y tomando en cuenta que existen celdas con valores iguales a 0 , se optó por complementar el índice de asociación mediante los estadísticos coeficiente de contingencia y V de Cramer; en ambos estadísticos se encontró una relación significativa entre la actitud del sentenciado hacia la sentencia impuesta y el cumplimiento de la pena.

Tabla 9. Coeficiente de relación entre el cumplimiento de la pena y la actitud de los sentenciados hacia la pena

\begin{tabular}{ll} 
ESTADÍSTICO VALOR & SIG. APROX. \\
\hline
\end{tabular}

Coeficiente de contingencia

\section{V de Cramer \\ 0.744 \\ 0.000}

En cuanto a la relación entre la actitud de los sentenciados y el cumplimiento de la pena de prestación de servicios a la comunidad, se encontró una relación significativa entre ambas variables (tablas núms. 8 y 9); esto implica que mientras más favorable sea la actitud del sentenciado hacia la pena impuesta, es decir, mientras se considere una pena justa, en retribución a la falta o delito cometido, el sentenciado tendrá una mayor disposición hacia su cumplimiento. Contrariamente, quienes consideran a la pena recibida como injusta e inmerecida, o como un abuso de parte de la justicia, entonces estas personas opondrán mayor resistencia hacia su cumplimiento; por tanto, tenderán a un mayor abandono de la ejecución. 


\section{Cumplimiento de las sentencias con prestación de servicios a la comunidad}

En general, de la muestra seleccionada, es decir de los 150 sentenciados de los establecimientos de medio libre y ejecución de penas limitativas de derechos de Huacho, Zarate, Surquillo, Independencia y El Callao, un 60\% no cumple la sentencia de prestación de servicios a la comunidad, frente a $40 \%$ de sentenciados que sí lo cumplen.

Si observamos el cumplimiento de las sentencias por establecimiento, tenemos que en el establecimiento de medio libre y de ejecución de penas limitativas de derechos de Huacho existe un $65 \%$ de cumplimiento de la sentencias de prestación de servicios a la comunidad, y sólo 35\% de incumplimiento de la misma. En el establecimiento de medio libre y de ejecución de penas limitativas de derechos de Zárate tenemos un $22.5 \%$ de cumplimiento frente a un $77.5 \%$ de sentenciados que incumplen la sentencia. En el establecimiento de medio libre y de ejecución de penas limitativas de derechos de Surquillo se observa un 59\% de cumplimientos de la sentencia de prestación de servicios a la comunidad, frente a $41 \%$ de incumplimientos. El establecimiento de medio libre y de ejecución de penas limitativas de derechos de Independencia, por su parte, muestra $42 \%$ de cumplimiento y $58 \%$ de incumplimiento de la sentencia. Por último, en el establecimiento de medio libre y de ejecución de penas limitativas de derechos de El Callao se observa el $29 \%$ de cumplimientos, frente a $71 \%$ de incumplimientos de la sentencia de prestación de servicios a la comunidad.

Tabla 10. Cumplimiento de sentencia en los establecimientos de medio libre y ejecución de penas limitativas de derechos (EML y EPLD) 


\begin{tabular}{lllll} 
EML & & NO CUMPLE & CUMPLE & TOTAL \\
\hline \hline \multirow{2}{*}{ Huacho } & Frecuencia & 7 & 13 & 20 \\
& \% cumplimiento & $35 \%$ & $65 \%$ & $100 \%$ \\
\hline \multirow{2}{*}{ Zárate } & Frecuencia & 31 & 9 & 40 \\
& \% cumplimiento & $77.5 \%$ & $22.5 \%$ & $100 \%$ \\
\hline Independencia & Frecuencia & 7 & 10 & 17 \\
& \% cumplimiento & $41 \%$ & $59 \%$ & $100 \%$ \\
\hline \multirow{2}{*}{ El Callao } & Frecuencia & 30 & 22 & 52 \\
& \% cumplimiento & $58 \%$ & $42 \%$ & $100 \%$ \\
\hline \hline
\end{tabular}

Finalmente, en cuanto al cumplimiento de las penas de prestación de servicios a la comunidad, se tiene en la muestra seleccionada que el $60 \%$ no cumple la sentencia de prestación de servicios a la comunidad, frente a un $40 \%$ de sentenciados, que sí lo cumplen. Este elevado porcentaje de incumplimiento se encuentra relacionado con el incumplimiento de las normas por parte de los actores de la ejecución de la sentencia, como son los establecimientos de medio libre y de ejecución de penas limitativas de derechos y las entidades receptoras; asimismo, se encuentra relacionado con la actitud del sentenciado hacia la pena recibida.

Es preciso agregar que durante la revisión documental en los establecimientos de medio libre y de ejecución de penas limitativas de derechos, se observó que en los mismos no se contaba con equipos de cómputo adecuados para el registro y seguimiento de los sentenciados, así como tampoco de sistemas automatizados que les permita realizar la tarea de manera eficiente, situación que se agrega a los motivos de incumplimiento de la pena de prestación de servicios a la comunidad.

Es indiscutible el hecho de que la justificación de la pena se halla en su propia necesidad; una comunidad que quisiera renunciar al poder punitivo se abandonaría a 
sí misma. La necesidad del derecho penal es un hecho empíricamente reconocido; sin embargo, este reconocimiento nada dice acerca de la forma de la eficacia de la pena; en especial si la necesidad de la misma para la existencia de la comunidad radica en su sola amenaza, en el hecho de su imposición o, por último, en la configuración de su ejecución. ${ }^{29}$

El reconocimiento empírico de la necesidad del poder punitivo no es suficiente para proporcionar una explicación respecto a la esencia y/o la finalidad de la obligación y la facultad estatal de aplicar penas. Así lo dice Mantovani ${ }^{30}$ al señalar que la necesidad de la pena, que se deduce de la correlación responsabilidad-pena como antítesis a la responsabilidad social o legal, según la Constitución es un elemento garantista no eliminable. Agrega que la abolición de la pena en sí y por sí, debería considerarse inconstitucional, siendo legítimas sólo las sanciones sustitutivas de la pena de detención.

La pena resulta entonces, la característica más importante del derecho penal, toda vez que la forma de control del delito hasta su actual desarrollo requiere necesariamente la aplicación de una pena.

Al respecto, Zaffaroni señala: "toda concepción de la pena es, necesariamente, una concepción del derecho penal, de su función y del modo de cumplir esa función". ${ }^{31} \mathrm{Y}$ Prado precisa que:

La pena es sólo una autoconstatación ideológica del Estado, de sus sistemas de valores, es por ello que el Estado tiende a no preocuparse por la efectividad de sus normas, ello también es síntoma de la imperfección del Estado social y democrático de todos los valores del sistema, y es ello justamente lo que produce la crisis del derecho y también su distanciamiento de la realidad social. ${ }^{32}$

No obstante, el Código Penal peruano de 1991, en su artículo IX del título preliminar, establece la función preventiva, protectora y resocializadora de la pena; esto es, la pena como instrumento que evitará la comisión de nuevos delitos, y además como instrumento de tratamiento del penado, que se reflejará con la

\footnotetext{
${ }^{29}$ Exposición de Motivos del Código Penal Decreto Legislativo 635, 8 de abril de 1991.

${ }^{30}$ Mantovani, Ferrando, Los principios del derecho penal, trad. de Martín Eduardo Botero, Lima, Editora y Distribuidora Ediciones Legales EIRL, 2015, p. 554.

${ }^{31}$ Villavicencio Terreros, Felipe, Derecho penal. Parte general, Lima, Editora Jurídica Grijley EIRL, 2006, p. 45.

32 Prado Saldarriaga, Víctor, Derecho penal, Lima, Editorial Aldas, 1998, p. 10.
} 
resocialización, siendo la pena de prestación de servicios a la comunidad una sanción acorde con esta función.

Es decir, la política criminal peruana, en oposición a la teoría de la retribución que para Kant la pena es retribución a la culpabilidad del sujeto, es el único fundamento, y es por ello que señala que si el Estado se disuelve, tiene que preocuparse de que tal culpabilidad quede retribuida, pues de otra manera el pueblo se haría partícipe de ella y recaería tal culpabilidad también sobre éste. Juan Bustos ${ }^{33}$ se adhiere a las teorías relativas o de la prevención que son utilitarias de la pena. Así lo afirma Prado $^{34}$ al señalar que los artículos I y IX del título preliminar le reconocen capacidades preventivo-generales. Esto es, la pena no es un fin, sino que tiene un fin; su justificación se encuentra en otro principio, que es la necesidad social.

Sin embargo, como dice Beccaria, la necesidad obliga a los hombres a asociarse, cediendo parte de la propia libertad aquello que es indispensable. El agregado de estas mínimas porciones posibles forma el derecho de castigar. El fundamento y límite de la punición es la necesidad de conservar la seguridad social, y las penas son tanto más justas cuanto más sagrada e inviolable sea la seguridad, y mayor la libertad que el soberano conserva a sus súbditos; ${ }^{35}$ deduciéndose así la obligación de indagar por razones que aseguren el cumplimiento de la sanción que se impone a quien cometió un delito.

\section{CONCLUSIONES}

Primera. Se ha probado que tanto las entidades receptoras como los establecimientos de medio libre y de ejecución de penas limitativas de derechos de la Dirección Regional Lima no cumplen con el proceso establecido referido a las acciones que cada institución debe realizar para asegurar el cumplimiento de la sentencia impuesta; asimismo, con el resultado de la prueba estadística aplicada se tiene que el incumplimiento del proceso normado está asociado al incumplimiento de la pena de prestación de servicios a la comunidad, toda vez que se ha verificado que cuando se ha dado cumplimiento al proceso normado se ha logrado un mayor cumplimiento de sentencias.

\footnotetext{
${ }^{33}$ Bustos Ramírez, Juan, “Estado actual de la teoría de la pena”, en Prado Saldarriaga, Víctor et al. (comps.), Derecho penal. Parte general, Lima, UNMSM-Editorial Grijley, 1995, pp. 612 y 613.

${ }^{34}$ Prado Saldarriaga, Víctor, Determinación judicial..., cit., p. 32.

${ }^{35}$ Beccaria, Cessare, De los delitos y las penas, trad. de Francisco Tomás y Valiente, Buenos Aires, Rodamillans Librería “El Foro”, 2004, pp. 50 y 51.
} 
Se comparte con Prado ${ }^{36}$ que la pena de prestación de servicios a la comunidad expresa una tendencia proactiva y de autorrealización del condenado; lo que importa si se reconoce que las penas y medidas alternativas a las penas privativas de libertad en el Perú son elementos esenciales de las políticas de despenalización; además, recogiendo la idea de Ariel Doti, ${ }^{37}$ citado por Prado, se estima que son suficientes para prevenir y suprimir el crimen; claro está, siempre que sean debidamente ejecutadas. En ese sentido, y a partir de los resultados del estudio, es notoria la necesidad de asegurar el cumplimiento de la pena; para ello es indispensable asegurar el cumplimiento del proceso normado.

Segunda. Las entidades receptoras no cumplen con devolver a la Dirección de Medio Libre, de manera mensual, las planillas de control laboral de los sentenciados, debidamente llenadas, que permita llevar un control continuo de la ejecución de la sentencia de prestación de servicios a la comunidad, función que se sustituye con la recopilación de las planillas de control laboral en las entidades receptoras, por parte del supervisor designado por la Dirección de Medio Libre, aunque se realiza en intervalos de tiempo demasiado espaciados, muchas veces mayores a tres meses.

En $47 \%$ no designa labores específicas, y mucho menos designa un responsable que controle y verifique el trabajo que realizan los sentenciados, pues sólo en $16 \%$ de los casos estudiados se ha verificado la designación de personal que controle la labor del sentenciado; incumplimiento de acciones normadas que se encuentran asociadas al incumplimiento de la pena impuesta por el órgano jurisdiccional.

La aceptación social de este tipo de sanciones es determinante para lograr el compromiso de las entidades receptoras, quienes al no cumplir con el proceso normado, están exhibiendo una falta de interés respecto de la función que viene cumpliendo el sentenciado asignado a su entidad; la Dirección de Medio Libre, además de registrar un alto número de ellas, tendría que idear estrategias para mejorar la comunicación y acortar las brechas con la entidad, de suerte que logre mayor vínculo, lo que se reflejaría en un mayor compromiso de estas entidades, y por consiguiente se mejoraría el proceso normado para la ejecución de la pena de prestación de servicios a la comunidad.

Tercera. La Dirección de Medio Libre de la Dirección Regional Lima, a 32\% del total de los casos estudiados, ubica al penado en una entidad receptora sin haberse

\footnotetext{
${ }^{36}$ Prado Saldarriaga, Víctor, Determinación judicial..., cit., p. 95.

${ }^{37}$ Ibidem, p. 79.
} 
determinado la fecha de inicio; en $49 \%$ no ubica al sentenciado en una entidad receptora cerca de su domicilio; a 69\% no le asigna una tarea tomando en cuenta sus aptitudes; asimismo, el 43\% de los establecimientos de medio libre y ejecución de penas limitativas de derechos no cumple con remitir la planilla correspondiente en la que la entidad receptora debe registrar el control laboral del sentenciado; en $70 \%$ de los casos se ha verificado la ausencia de supervisión laboral en las entidades receptoras, y en $61 \%$ de los casos se incumple con notificar al sentenciado que deja de cumplir con la prestación de servicios a la comunidad.

La ubicación del sentenciado en una entidad receptora se realiza luego de la entrevista y evaluación del sentenciado que permite conocer las aptitudes, el lugar de residencia y los intereses, para asignarle el área laboral más próxima a su perfil y domicilio. Este procedimiento es urgente que se ejecute, en tanto que en el entorno muchas personas se trasladan sólo con el dinero ajustado para sus movilidades, y en el caso de los sentenciados es necesario señalar que no cuentan con recursos económicos. Por lo cual es urgente exhortar a las autoridades que tienen a cargo la función de ejecución de la prestación de servicios a la comunidad, a que se cumpla, porque si se parte de la premisa de que muchas personas, no obstante no estar en calidad de sentenciadas, no tienen dinero ni para la movilidad, no se puede esperar menos de los sentenciados, siendo el caso que si se les ubica en entidades receptoras muy lejanas a su domicilio, hay más probabilidad de que no asistan a cumplir con sus jornadas laborales por falta de dinero para trasladarse.

Cuarta. Se ha probado que existe una relación entre la actitud de los penados con sentencias a prestación de servicios comunitarios y el cumplimiento de sus sentencias en los establecimientos de la Dirección de Medio Libre de la Oficina Regional Lima del Instituto Nacional Penitenciario durante el periodo 2007; dado que se ha demostrado que cuando es más favorable la actitud del sentenciado hacia la pena impuesta, por considerarla justa, mayor es su disposición hacia el cumplimiento de la misma.

Este tipo de pena requiere del compromiso del sentenciado para su eficaz cumplimiento; por ello, se observa un mayor cumplimiento de las jornadas cuando hay mayor satisfacción con la pena impuesta, lo cual forma parte también de la aceptación social de este tipo de penas por parte del sentenciado y de sus abogados. Para ello es necesario que las autoridades del INPE programen y organicen campañas de difusión acerca de las bondades de la pena.

Quinta. Se ha probado que una mayor proporción de sentenciados a prestación de 
servicios a la comunidad incumple la sentencia en la Dirección de Medio Libre de la Dirección Regional Lima del Instituto Nacional Penitenciario durante el periodo 2007, pues el $60 \%$ de los sentenciados a la pena de prestación de servicios a la comunidad no cumple la pena impuesta, frente al 40\%, que sí la cumple.

El novísimo decreto legislativo que regula la ejecución de las penas de prestación de servicios a la comunidad y de limitación de días libres, en su afán de asegurar el cumplimiento de la pena de prestación de servicios a la comunidad, ha precisado plazos y delimitado expresamente las funciones del juzgador, de la Dirección de Medio Libre y de las Unidades Beneficiarias; se destaca la decisión de sancionar con multa no menor de cinco ni mayor de diez unidades de referencia procesal, a la unidad beneficiaria que se oponga o resista efectivizar la sanción impuesta o falta a su deber de informar al juez cuando lo requiera, sin perjuicio de la acción penal que corresponda.

Al respecto, tal disposición permite preguntar si su contenido podría afectar la adherencia de interesados en el Registro Nacional de Unidades Beneficiarias, y de ser así, cuánto podría empeorar el cumplimiento de la pena de prestación de servicios a la comunidad; se estima que sancionar a quienes coadyuvan para el cumplimiento de una pena como es la prestación de servicios a la comunidad o limitación de días libres, no es la mejor alternativa, pues debe estimarse el hecho de que cada institución que se constituye como unidad beneficiaria tiene su propia finalidad, sea de salud, religiosa o educativa, considerando que, como se ha mencionado en líneas anteriores, la tarea debe estar orientada a sensibilizar y lograr compromiso.

\section{BIBLIOGRAFÍA}

BeCCARIA, Cessare, De los delitos y las penas, trad. de Francisco Tomás y Valiente, Buenos Aires, Rodamillans S. R. L. Librería “El Foro”, 2004.

Bustos Ramírez, Juan, “Estado actual de la teoría de la pena”, en Prado SaldarRiagA, Víctor et al. (comp.), Derecho penal. Parte general, Lima, UNMSM-Editorial Grijley, 1995.

García ValdeZ, Carlos, Alternativas legales a la privación de la libertad clásica, en prevención y teoría de la pena, Santiago de Chile, Editorial Jurídica Cono Sur, 1995.

Hurtado Pozo, José y PRADO SALDARRIAGA, Víctor, Manual de derecho penal. Parte general, 4a. ed., Lima, IDEMSA, 2011, t II.

Mantovani, Fernando, Los principios del derecho penal, trad. de Martín Eduardo Botero, Lima, Editora y Distribuidora Ediciones Legales EIRL, 2015. 
Esta revista forma parte del acervo de la Biblioteca Jurídica Virtual del Instituto de Investigaciones Jurídicas de la UNAM

Mir PUIG, Santiago, Derecho penal. Parte general, 9a. ed., Buenos Aires, Euros Editores S. R. L., 2011.

Prado Saldarriaga, Víctor, "El sistema de penas", Comentarios al Código Penal de 1991, Lima, Editorial Alternativas, 1993.

-_- BojóRquez, Uldarrico y Solís, Edgar, Derecho penal. Parte general, Lima, Editorial Grijley, 1995.

-_-, Derecho penal, Lima, Editorial Aldas, 1998.

_-_, Determinación judicial de la pena y acuerdos plenarios, Lima, Idemsa, 2010.

RAmos SUYo, Juan, Manual de excarcelación ciencia penitenciaria, Lima, Editora FECAT, 2000.

Riega-Viru, Yasmina, Penas limitativas de derechos en el Perú, tesis para optar el grado académico de maestra en derecho penal, Lima, Universidad Nacional Federico Villarreal, 2004.

RUBio CorReA, Marcial, Para conocer la Constitución de 1993, 2a. ed., Lima, Editorial Pontificia Universidad Católica del Perú, 2008.

VILLA SteIN, Javier, Derecho penal. Parte general, Lima, Ara Editores E. I. R. L., 2014.

Villavicencio Terreros, Felipe, Derecho penal. Parte general, Lima, Editora Jurídica Grijley EIRL, 2006.

Decreto Legislativo Núm. 635, Diario Oficial El Peruano, Lima, 4 de agosto de 1991.

Decreto Legislativo Núm. 1191, Diario Oficial El Peruano, Lima, 22 de agosto de 2015.

Ley Núm. 27186 (Ley que modifica los artículos 32 y 52 del Código Penal respecto a la aplicación de las penas limitativas de derechos, por la modalidad de prestación de servicios a la comunidad y limitación de días libres).

Código de Ejecución Penal, Decreto Legislativo Núm. 654, Diario Oficial El Peruano, Lima, 2 de agosto de 1991.

Ley 27030 Ley de Ejecución de Penas de Servicios a la Comunidad y de Limitación de Días Libres, Diario Oficial El Peruano, Lima, promulgado el 18 de diciembre de 1998.

Decreto Supremo 015-2003-JUS Aprueban el Reglamento del Código de Ejecución Penal, Diario Oficial El Peruano, Lima, 11 de septiembre de 2003. 
Ley 27935 Ley que modifica artículos de la Ley de Ejecución de las penas de Prestación de Servicios a la Comunidad y de Limitación de Días Libres, Diario Oficial El Peruano, Lima, 12 de febrero de 2003.

Decreto Supremo Núm. 022-2003-JUS. “Aprueban reglamento para ejecución y supervisión de penas de prestación de servicios a la comunidad y de limitación de días libres a cargo de municipalidades y la PNP", Diario Oficial El Peruano, Lima, 7 de noviembre de 2003.

Dirección del Medio Libre, Instituto Nacional Penitenciario. Entidades Receptoras a nivel Nacional, julio de 2012, http://WwW.inpe.gob.pe/contenidos.php?id=629\&np=35\&direccion=1. 